\title{
Epidemiologic History and Genetic Diversity Origins of Chikungunya and Dengue Viruses, Paraguay
}

Tiago Gräf, ${ }^{1}$ Cynthia Vazquez, ${ }^{1}$ Marta Giovanetti, ${ }^{1}$ Fernanda de Bruycker-Nogueira,,${ }^{1}$ Vagner Fonseca, ${ }^{1}$ Ingra Morales Claro, Jaqueline Goes de Jesus, Andrea Gómez, Joilson Xavier, Marcos Cesar Lima de Mendonça, Shirley Villalba, Juan Torales, Maria Liz Gamarra, Julien Thézé, Ana Maria Bispo de Filippis,

Vasco Azevedo, Tulio de Oliveira, Leticia Franco, Carlos F. Campelo de Albuquerque, Sandra Irala, Edward Charles Holmes, Jairo Andrés Méndez Rico, Luiz Carlos Junior Alcantara

Paraguay has been severely affected by emergent Zika and chikungunya viruses, and dengue virus is endemic. To learn more about the origins of genetic diversity and epidemiologic history of these viruses in Paraguay, we deployed portable sequencing technologies to strengthen genomic surveillance and determine the evolutionary and epidemic history of arthropod-borne viruses (arboviruses). Samples stored at the Paraguay National Central Laboratory were sequenced and subjected to phylogenetic analysis. Among 33 virus genomes generated, we identified 2 genotypes of chikungunya and 2 serotypes of dengue virus that circulated in Paraguay during 20142018; the main source of these virus lineages was estimated to be Brazil. The evolutionary history inferred by our analyses precisely matched the available travel history of the patients. The genomic surveillance approach used was valuable for describing the epidemiologic history of arboviruses and can be used to determine the origins and evolution of future arbovirus outbreaks.

Chikungunya virus (CHIKV), dengue virus (DENV), and Zika virus (ZIKV) are 3 of the most common arthropod-borne viruses (arboviruses)

Author affiliations: Fundação Oswaldo Cruz, Salvador, Brazil

(T. Gräf, J.G. de Jesus); Fundação Oswaldo Cruz, Rio de Janeiro,

Brazil (C. Vazquez, M. Giovanetti, F. de Bruycker-Nogueira,

V. Fonseca, J. Xavier, M.C.L. de Mendonça, A.M. Bispo de

Filippis, L.C.J. Alcantara); Laboratorio Central de Salud Pública,

Asunción, Paraguay (C. Vazquez, A. Gómez, S. Villalba,

J. Torales, M.L. Gamarra); Instituto de Ciências Biológicas,

Universidade Federal de Minas Gerais, Belo Horizonte, Brazil

(M. Giovanetti, V. Fonseca, J. Xavier, V. Azevedo, L.C.J. Alcantara);

University of KwaZulu-Natal, Durban, South Africa (V. Fonseca,

T. de Oliveira); Universidade de São Paulo, São Paulo, Brazil

(I.M. Claro); University of Oxford, Oxford, UK (J. Thézé); University that infect humans. All are transmitted by the anthropophilic and urban-adapted Aedes aegypti and Ae. albopictus mosquito vectors (1). Driven by human movement and climate trends, the distribution of these mosquitoes is expanding along with the arboviruses they transmit (2). In Latin America, CHIKV and ZIKV have emerged since the mid2000s, joining DENV, which is already endemic there (3). In this region, only Uruguay and Chile did not report autochthonous transmissions of one of these arboviruses during 2014-2019, highlighting the current state of endemicity (4).

Paraguay is a landlocked country in the center of South America; it borders Bolivia, Brazil, and Argentina. DENV is endemic to Paraguay, and all 4 serotypes (DENV-1-4) have been detected there; in some seasons, multiple serotypes co-circulate $(5,6)$. Phylogenetic analysis has shown that DENV genetic diversity in Paraguay is closely related to that in neighboring countries, particularly Brazil $(7,8)$. However, more genomic surveillance studies in Paraguay are needed to learn more about this epidemiologic pattern. Cases

of Washington, Seattle, Washington, USA (T. de Oliveira); Organización Panamericana de la Salud /Organización Mundial de la Salud, Panama City, Panama (L. Franco); Organização Pan-Americana da Saúde/Organização Mundial da Saúde, Brasília, Brazil (C.F. Campelo de Albuquerque); Dirección General de Vigilancia de la Salud Paraguay, Asunción (S. Irala); The University of Sydney, Sydney, New South Wales, Australia E.C. Holmes); Pan American Health Organization/World Health Organization, Washington, DC, USA (J.A.M. Rico)

DOI: https://doi.org/10.3201/eid2705.204244

${ }^{1}$ These first authors contributed equally to this article. 
of chikungunya fever in Paraguay were first reported in June 2014; autochthonous cases were first detected in 2015, and CHIKV caused seasonal outbreaks every year until 2018. Zika was first detected in November 2015, and autochthonous infections were confirmed soon after (9). To date, however, little is known about the genetic diversity of CHIKV and ZIKV that circulate in Paraguay.

The potential triple epidemic scenario (i.e., CHIKV, DENV, ZIKV) in Paraguay could pose serious public health and economic burdens. Arbovirus surveillance is critical for assisting health services with preparedness, providing key information about the seasonality of infections and diversity of circulating viral lineages. When resources allow, such surveillance can now involve genomic surveillance via portable sequencing technologies. For example, this approach was successfully used to study the ZIKV epidemic in the Americas $(10,11)$, the reemergence of yellow fever virus in Brazil $(12,13)$, and recurrent outbreaks of CHIKV in several regions of Brazil (14-16).

To help reinforce arbovirus surveillance in Paraguay, we performed portable genome sequencing under the scope of the ZIBRA project (http://zibraproject.org) at the Laboratorio Central de Salud $\mathrm{Pu}-$ blica in Asunción, Paraguay. During July 16-20, 2018, a team of molecular biologists from Brazil and Paraguay worked on a group of samples selected to determine the recent history of arboviruses in the country, generating 33 viral genomes and building capacity skills among the local laboratory staff. We report the analysis of the origins and spread of CHIKV in Paraguay as well as the current dynamics of DENV. The project was reviewed and approved by the Comissão Nacional de Ética em Pesquisa (CONEP) from the Brazilian Ministry of Health as part of the arbovirus genomic surveillance efforts within the terms of CONEP Resolution 510/2016 by the Pan American Health Organization Ethics Review Committee (PAHO-2016-08-0029) and by the Paraguayan Ministry of Public Health and Social Welfare (MSPyBS/ S.G. no. 0944/18).

\section{Methods}

\section{Sample and Data Collection}

This study was necessarily based on convenience sampling; de-identified samples were obtained from material exceeding the routine number of arbovirus diagnoses and stored at the Laboratorio Central de Salud Publica de Asunción, Paraguay, which concentrates biological samples collected throughout the country. On the basis of resources and time availability, we selected 50 acute-phase serum samples that were positive for DENV or CHIKV with PCR cycle threshold $\left(\mathrm{C}_{t}\right)$ values $<28$ at the time of diagnosis. Using epidemiologic data, we chose samples to represent geographic departments in Paraguay with the highest number of cases. ZIKV-positive samples with low $C_{t}$ and historical samples for DENV were unavailable; hence, for DENV, we studied only the 2018 epidemic. The Direccion General de Vigilancia de la Salud of Paraguay provided temporal data on the incidence of chikungunya and dengue cases by department within Paraguay.

\section{Virus Amplification and Whole-Genome Sequencing}

We extracted viral RNA from the selected samples by using the QIAamp Viral RNA Mini Kit (QIAGEN, https:/ / www.qiagen.com) and subjected the RNA to real-time reverse transcription quantitative PCR to detect CHIKV and DENV serotypes 1-4 as described previously (17-19). To increase the genome coverage, we selected only samples with $C_{t} \leq 35$ for sequencing. Extracted RNA was converted to cDNA by using the Protoscript II First Strand cDNA Synthesis Kit (New England Biolabs, Inc., https://www.neb.uk.com) and random hexamer priming. We attempted wholegenome amplification by multiplex PCR as previously described (20).

We purified amplicons by using 1x AMPure XP Beads (Beckman Coulter, https://www.beckman. com) and quantified them on a Qubit 3.0 fluorimeter by using a Qubit dsDNA HS Assay Kit (ThermoFisher Scientific, https://www.thermofisher.com). We performed DNA library preparation by using a Ligation Sequencing Kit and Native Barcoding Kit (NBD103; Oxford Nanopore Technologies, https:// nanoporetech.com). We generated sequencing libraries from the barcoded products by using the Genomic DNA Sequencing Kit SQK-MAP007/SQK-LSK208 and loaded them into an R9.4 flow cell (Oxford Nanopore Technologies).

\section{Generation of Consensus Sequences}

We base-called raw files by using Albacore software, demultiplexed and trimmed by using Porechop software (https://github.com) and then mapped with Burrows-Wheeler Aligner software to a reference genome. On the basis of PCR analyses, we used GenBank accession nos. KP164568 for CHIKV, KF672760 for DENV-1, and JN559741 for DENV-4 as reference sequences. To detect single-nucleotide variants to the reference genome, we applied Nanopolish software variant calling (https://nanoporetech.com) to the assembly. Nonoverlapped primer binding sites and 
sites for which coverage was $<20 \times$ were replaced with ambiguity code $\mathrm{N}$.

\section{Phylogenetic Analyses}

We first investigated sequence genotypes by using the arbovirus genotyping tool (21). To investigate the origins and spatial dynamics of arboviruses in Paraguay, we downloaded all sequences assigned as CHIKV, DENV-1, and DENV-4 from GenBank. We excluded sequences without sampling date and location and sequences covering $<50 \%$ of the virus genome. Sequence alignment was performed by using MAFFT (22) (FFT-NS-2 algorithm) and visually inspected in Aliview (23). We estimated maximum-likelihood phylogenies in IQ-TREE (24) by using the best-fit model of nucleotide substitution as indicated by the ModelFinder application (implemented in IQ-TREE). Branch support was assessed by the SH-like approximate-likelihood ratio test, and we submitted highly supported $(>0.9)$ clades containing the DENV genomes from Paraguay (Appendix 1 Figure 1, https:/ / wwwnc.cdc.gov/EID/article/27/5/20-4224-App1. pdf) and the clades of CHIKV from the Americas to TempEst (25) to assess the strength of temporal signal in these data.

Time-scaled phylogenetic trees were inferred by using the BEAST package (26). We chose the uncorrelated relaxed molecular clock model as indicated by the marginal likelihood estimation model test procedure. We also used the codon-based SRD06 model of nucleotide substitution and the nonparametric Bayesian Skygrid coalescent model. A discrete phylogeographical model (27) was used to reconstruct the spatial diffusion of the virus across the compiled dataset sampling locations (Appendix 2, https:/ / wwwnc.cdc. gov/EID/article/27/5/20-4224-App2.xlsx). Phylogeographic analyses were performed by applying an asymmetric model of location transitioning coupled with the Bayesian stochastic search variable selection procedure. We complemented this analysis with Markov jump estimation that counts location transitions per unit time along the tree. We ran Monte Carlo Markov chains long enough to ensure stationarity and an adequate effective sample size of $>200$.

\section{Results}

Of the 50 samples tested, 25 were positive for CHIKV, 14 for DENV-1, and 11 for DENV-4. For positive samples, the average PCR $C_{t}$ value was 26.36 (range 1637 ). From the 50 samples, we were able to generate 33 complete or near-complete genome sequences (17 CHIKV and 16 DENV genomes) (Table). The GenBank accession numbers of newly generated sequences are MT038393-409 (CHIKV) and MT040672-87 (DENV). The collection dates of the samples sequenced were November 3, 2014, through July 10, 2018, and locations covered 15 municipalities and 8 departments (the first-level administrative subdivisions) of Paraguay (Figure 1). Women accounted for $58 \%$ of the samples, and the median patient age was 34 years. A TempEst analysis of all arbovirus lineages found here revealed a strong correlation between the sampling time and the root-to-tip divergence (Appendix 1 Figure 2).

\section{The CHIKV Epidemic in Paraguay during 2014-2018}

Of the $17 \mathrm{CHIKV}$ genomes, 12 were classified as Asian genotype (sampled during 2014-2016) and 5 as East/Central/South African (ECSA) genotype (sampled during 2018). The oldest CHIKV sample analyzed (patient PY45) was obtained in November 2014 from the department of Amambay and was identified as an Asian genotype (Figure 1). However, autochthonous transmission of CHIKV was not confirmed until February 2015, followed by an increased number of reported infections (9) (Figure 2, panel A). Phylogeographic analysis revealed that the most likely origin of PY45 was Central or South America (Figure 3, panel A). The travel history for PY45 is in agreement with these results because the patient reported having visited Panama and San Andrés, a Colombian cluster of islands in the Caribbean region. In November 2014, another introduction of CHIKV in Paraguay was detected in the Central Department. That sequence (patient PY44) clustered with high support (posterior probability $[\mathrm{PP}]=1$ ) among sequences from Colombia and 1 sequence from $\mathrm{Ni}$ caragua, and the ancestral state of the most recent common ancestor (MRCA) of this clade was South America $(\mathrm{PP}=0.8)$. Patient PY44 reported traveling to Cartagena, Colombia, supporting the origin estimated by the phylogeographic analysis.

In 2015, a large CHIKV epidemic occurred in Paraguay, resulting in $\approx 10,000$ cases (suspected and confirmed); the main affected departments were Central, Asunción, and Paraguarí (Figure 2, panel A). All genomes generated from the 4 samples from 2015 were classified as members of the Asian genotype and grouped together with high support $(\mathrm{PP}=1)$ (Figure 3, panel A) in a clade for which time to MRCA (tMRCA) was October 2014 (95\% highest posterior density [HPD] May 2014 to November 2014) (Figure 2, panel B). From our analysis, we estimated that the geographic origin of the variant circulating in Paraguay in 2015 was Puerto Rico $(\mathrm{PP}=0.98$ ) (Figure 3, panel A). The first patient with autochthonous 
CHIKV infection in Paraguay is believed to be the housemaid of a family returning from Puerto Rico in October 2014, who sought healthcare services for symptoms of chikungunya fever. CHIKV infections were confirmed for the housemaid and the family, and our phylogenetic analysis confirmed this epidemiologic history.

The time distributions of CHIKV infection cases from 2016 were very similar to those in 2015 (Figure 2 , panel A), although they did reveal that at least 2 lineages were circulating in the country (Figure 3, panel A). A new introduction is likely to have occurred in the Paraguarí Department at the mean time point of November 2015 (95\% HPD June 2015 to January 2016); the most likely place of origin was Central America ( $\mathrm{PP}=0.76$ ) (Figure 3, panel A). However, the sequence from Amambay Department, isolated in 2014, is positioned basally to the Paraguarí cluster, suggesting that the same variant persisted in the country up to 2016. Year-round persistence of a CHIKV strain is clearly observed in the Central/ Asunción Department cluster in which the genome

Table. Patient demographic and virus sequencing data for samples from the Laboratorio Central de Salud Publica de Asunción, Paraguay, 2014-2018*

\begin{tabular}{|c|c|c|c|c|c|c|c|}
\hline Sample & Virus & Department, municipality & Collection date & $\begin{array}{l}\text { Patient age, } \\
\text { y/sex }\end{array}$ & $\mathrm{C}_{\mathrm{t}}$ & Reads & $\begin{array}{c}\text { Genome } \\
\text { coverage, \% }\end{array}$ \\
\hline PY02 & $\begin{array}{l}\text { CHIKV-Asian } \\
\text { genotype }\end{array}$ & Paraguarí, Yaguarón & 2016 Jan 20 & $40 / \mathrm{M}$ & 23.6 & 204,763 & 88.1 \\
\hline PY03 & $\begin{array}{l}\text { CHIKV-Asian } \\
\text { genotype }\end{array}$ & Paraguarí, Yaguarón & 2016 Jan 21 & $67 / \mathrm{M}$ & 16.9 & 215,137 & 87.0 \\
\hline PY06 & $\begin{array}{l}\text { CHIKV-Asian } \\
\text { genotype }\end{array}$ & Paraguarí, Yaguarón & 2016 Feb 16 & 9/M & 26.9 & 282,182 & 88.3 \\
\hline PY07 & $\begin{array}{l}\text { CHIKV-Asian } \\
\text { genotype }\end{array}$ & Paraguarí, Yaguarón & 2016 Fab 19 & $34 / F$ & 29.7 & 267,784 & 87.2 \\
\hline PY08 & $\begin{array}{l}\text { CHIKV-Asian } \\
\text { genotype }\end{array}$ & Paraguarí, Yaguarón & 2016 Feb 22 & $39 / F$ & 30.2 & 142,555 & 87.1 \\
\hline PY09 & $\begin{array}{l}\text { CHIKV-Asian } \\
\text { genotype }\end{array}$ & Asunción, Asunción & 2016 Mar 21 & $27 / F$ & 28 & 265,596 & 87.9 \\
\hline PY12 & CHIKV-ECSA/BR & Amambay, Pedro Juan Caballero & 2018 & 21/M & 29 & 236,285 & 84.8 \\
\hline PY13 & CHIKV-ECSA/BR & Amambay, Pedro Juan Caballero & 2018 Jun 25 & $35 / F$ & 28 & 175,112 & 85.3 \\
\hline PY15 & CHIKV-ECSA/BR & Amambay, Bella Vista Norte & 2018 Jun 29 & $40 / F$ & 34 & 17,030 & 70.9 \\
\hline PY17 & CHIKV-ECSA/BR & Amambay, Bella Vista Norte & 2018 Jul 3 & 22/M & 34 & 320,142 & 86.8 \\
\hline PY18 & CHIKV-ECSA/BR & Amambay, Bella Vista Norte & 2018 Jul 10 & $57 / \mathrm{M}$ & 29 & 315,588 & 86.0 \\
\hline PY19 & DENV-4 & Guairá, Villarrica & 2018 Apr 23 & $38 / F$ & 23 & 22,041 & 82.3 \\
\hline PY21 & DENV-4 & Guairá, Villarrica & 2018 Apr 26 & $68 / F$ & 22 & 21,042 & 96.0 \\
\hline PY22 & DENV-4 & Guairá, Villarrica & 2018 Apr 27 & $52 / \mathrm{M}$ & 22 & 13,213 & 96.0 \\
\hline PY23 & DENV-4 & Central, San Lorenzo & 2018 May 6 & 19/M & 27 & 11,548 & 74.6 \\
\hline PY24 & DENV-1 & $\begin{array}{c}\text { San Pedro, San Pedro De } \\
\text { Ycuamandyju }\end{array}$ & 2018 May 4 & $29 / F$ & 20 & 7,265 & 89.1 \\
\hline PY25 & DENV-4 & Central, San Lorenzo & 2018 May 5 & $38 / F$ & 21 & 17,299 & 96.0 \\
\hline PY27 & DENV-4 & $\begin{array}{c}\text { Alto Paraná, Domingo Martinez } \\
\text { De Irala }\end{array}$ & 2018 May 9 & $27 / F$ & 19 & 21,188 & 96.0 \\
\hline PY28 & DENV-4 & Alto Paraná, Hernandarias & 2018 May & 30/M & 21 & 22,800 & 86.6 \\
\hline PY31 & DENV-4 & Alto Paraná, Hernandarias & 2018 May 22 & 14/M & 32 & 8,770 & 95.9 \\
\hline PY32 & DENV-4 & Central, San Lorenzo & 2018 May 31 & 28/M & 28 & 6,907 & 96.0 \\
\hline PY33 & DENV-1 & Asunción, Asunción & 2018 May 31 & $3 / \mathrm{F}$ & 22 & 9,846 & 76.8 \\
\hline PY34 & DENV-4 & $\begin{array}{l}\text { Alto Paraná, Juan Leon } \\
\text { Mallorquin }\end{array}$ & 2018 May 28 & $47 / F$ & 26 & 7,945 & 96.0 \\
\hline PY35 & DENV-1 & Itapúa, Encarnacion & 2018 Jun 7 & $62 / F$ & 23 & 119,293 & 89.1 \\
\hline PY36 & DENV-1 & Itapúa, Encarnacion & 2018 Jun 8 & $61 / \mathrm{M}$ & 23 & 6,448 & 76.8 \\
\hline PY38 & DENV-1 & Itapúa, Cambyreta & 2018 Jun 8 & $6 / F$ & 25 & 111,057 & 89.1 \\
\hline PY43 & DENV-1 & Guairá, Villarrica & 2018 Jun 4 & $53 / F$ & 25 & 8,779 & 89.1 \\
\hline PY44 & $\begin{array}{l}\text { CHIKV-Asian } \\
\text { genotype }\end{array}$ & Central, Luque & 2014 Nov 30 & $33 / F$ & 24 & 13,687 & 85.1 \\
\hline PY45 & $\begin{array}{l}\text { CHIKV-Asian } \\
\text { genotype }\end{array}$ & Amambay, Pedro Juan Caballero & 2014 Nov 3 & $54 / \mathrm{M}$ & 24 & 12,214 & 86.6 \\
\hline PY47 & $\begin{array}{l}\text { CHIKV-Asian } \\
\text { genotype }\end{array}$ & Central, Guarambare & 2015 Apr 26 & 25/M & 17 & 9,536 & 85.2 \\
\hline PY48 & $\begin{array}{l}\text { CHIKV-Asian } \\
\text { genotype }\end{array}$ & Central, Fernando De La Mora & 2015 Apr 28 & $50 / F$ & 18 & 6,002 & 86.6 \\
\hline PY49 & $\begin{array}{l}\text { CHIKV-Asian } \\
\text { genotype }\end{array}$ & Central, Fernando De La Mora & 2015 May 3 & $12 / F$ & 27 & 53,928 & 86.4 \\
\hline PY50 & $\begin{array}{l}\text { CHIKV-Asian } \\
\text { genotype }\end{array}$ & Central, Fernando De La Mora & 2015 May 6 & $25 / F$ & 16 & 49,813 & 86.8 \\
\hline
\end{tabular}




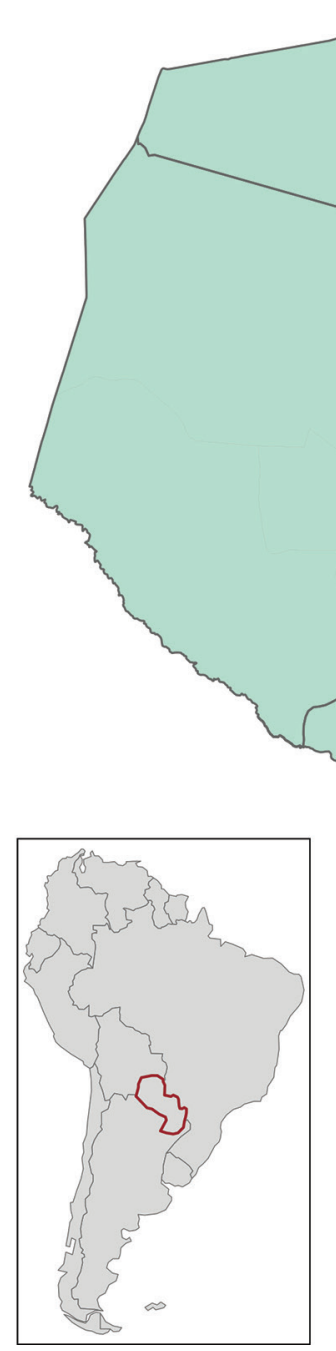

Genomes generated

DENV-1

DENV-4

CHIKV, Asian genotype

CHIKV, ECSA genotype

- $\bigcirc 00$

$\begin{array}{lllll}1 & 2 & 3 & 4 & 5\end{array}$

Brazil

isolated in 2016 clustered with the genomes isolated in 2015 (Figure 3, panel A).

Besides the Asian genotype of CHIKV, an outbreak of the ECSA genotype occurred in Paraguay in 2018. After a year of very few CHIKV infections in 2017 (Figure 2, panel A), a new outbreak was observed in 2018 (although milder than that of 2015 and 2016), and the main affected department was Amambay. Five genomes from this department revealed circulation of the CHIKV ECSA genotype in 2018, and the mean tMRCA of this cluster was December 2017 (95\% HPD July 2017 to April 2018) (Figure 2, panel B). The source of introduction of this new CHIKV lineage in Paraguay was estimated to be Brazil, most likely the Northeast Region ( $\mathrm{PP}=0.64)$, or perhaps the North Region (PP = 0.32) (Figure 3, panel B).

We also summarized all geographic locations that had significantly (Bayes factor $>3$ ) seeded new CHIKV lineages to Paraguay and superimposed it onto the
Figure 1. Geopolitical map of Paraguay showing locations of sampling for dengue virus (DENV) and chikungunya virus (CHIKV). Circle sizes are scaled to represent the number of genomes isolated in each municipality. Numbers inside triangles indicate sampled departments: 1, Amambay; 2, San Pedro; 3, Alto Paraná; 4, Itapúa; 5, Guairá; 6, Paraguarí; 7, Central; 8, Asunción. Callout map shows the Central and Asunción Departments of Paraguay; inset map shows the location of Paraguay in South America. 
were higher at the beginning of each year, except for 2017 when the DENV season was atypically mild. Our sampling from 2018 captured the 2 DENV serotypes (DENV-1 and DENV-4) circulating in the country (9), and molecular clock analyses estimated that DENV-4 was introduced in Paraguay just before the beginning of the 2018 outbreak, whereas DENV-1 was already circulating in 2017 (Figure 4, panel B).

DENV-1 and DENV-4 sequences from Paraguay clustered together with high support $(\mathrm{PP}>0.9)$ and belonged to genotypes $\mathrm{V}$ and II, respectively, which predominate in Latin America (Figure 5). The most likely origin of the DENV-1 strain circulating in Paraguay in 2018 was estimated to be Brazil (PP $=0.75)$ (Figure 5, panel A), and the mean tMRCA was estimated to be October 2016 (95\% HPD February 2016 to May 2017) (Figure 4, panel B). DENV-4 was also estimated to have an origin in Brazil; the best-supported regions of origin were Central-West $(\mathrm{PP}=0.64)$ and North $(\mathrm{PP}=0.34)$ (Figure 5, panel B). The mean tMRCA of DENV-4 was September 2017 (95\% HPD April 2017 to February 2018), $\approx 1$ year later than DENV-1. Examining the DENV-4 cluster in Paraguay in more detail revealed that sequences from the Alto Paraná Department are basal and that sequences from the Central and Guairá Departments group together in a highly supported $(\mathrm{PP}>0.9)$ and distal cluster (Figure 5, panel B). Alto Paraná borders Brazil, and although not formally tested because of the small number of sequences, Alto Paraná could be the point of introduction of the current DENV-4 lineage into Paraguay.

\section{Discussion}

The first CHIKV outbreaks in the Americas (the Asian genotype) were reported for the French Caribbean islands of Saint Martin and Martinique in December 2013 (28). The virus rapidly spread throughout the Caribbean and Central America in 2014, and autochthonous transmissions were reported in almost all countries/territories of these regions. In 2014, Paraguay reported imported cases only, mostly in persons with a history of travel to Central America or the Caribbean. Our analysis of virus sequences from 2 of these persons with imported cases, and the virus phylogenetic relatedness to foreign viruses, matched the travel history with precision. In addition, the estimated origin of the first outbreak of CHIKV in Paraguay in 2015 agreed both in time (October 2015) and location (Puerto Rico) with the travel data collected by the Paraguay surveillance system.

The CHIKV epidemic in Paraguay in 2016 was very similar to that in 2015, when the most affected departments were Central, Asunción, and Paraguarí. These neighboring departments are located in the most densely populated region of Paraguay, which might lead to consecutive outbreaks. In our sampling, most sequences from 2016 were from the Paraguarí Department and formed a separate clade

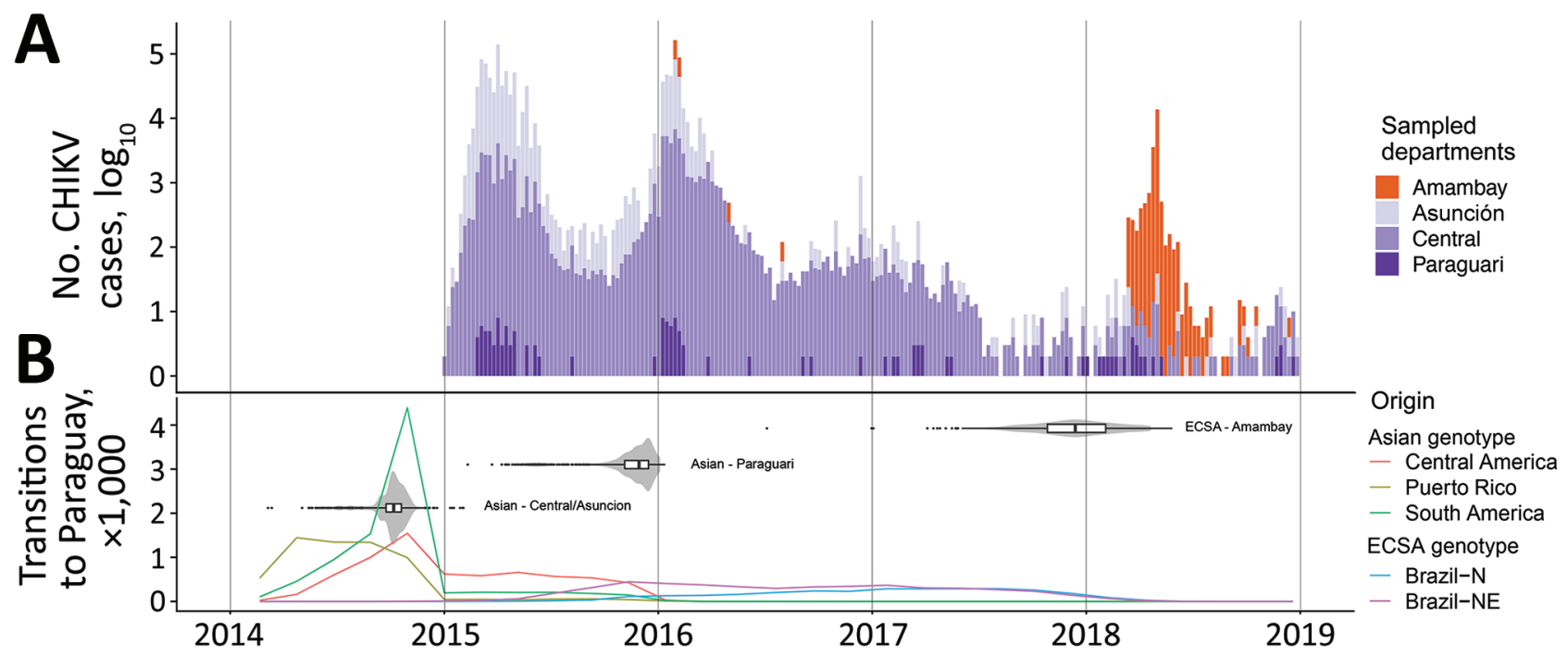

Figure 2. Chikungunya virus (CHIKV) outbreaks in Paraguay during 2014-2018 and the spatial-temporal history of virus diffusion. A) Total number of cases of CHIKV infection reported by epidemiologic week in the departments from which genome sequences were available. B) Location transitions to Paraguay inferred from the posterior distribution of phylogenetic trees by the Markov jump approach, and the time to most recent common ancestor for the CHIKV clusters detected in the country. Lines are colored according to the origin of the estimated transition toward Paraguay. Violin plots show $95 \% \mathrm{Cls}$ with internal boxplots showing median and interquartile ranges. Brazil-N, Brazil North Region; Brazil-NE, Brazil Northeast Region; ECSA, East/Central/South African genotype. 
A

Central America Dominican Republic

Greater Antilles

Leeward Islands

Lucayan Archipelago

North America

Oceania

Paraguay

Puerto Rico

South America

Windward Islands
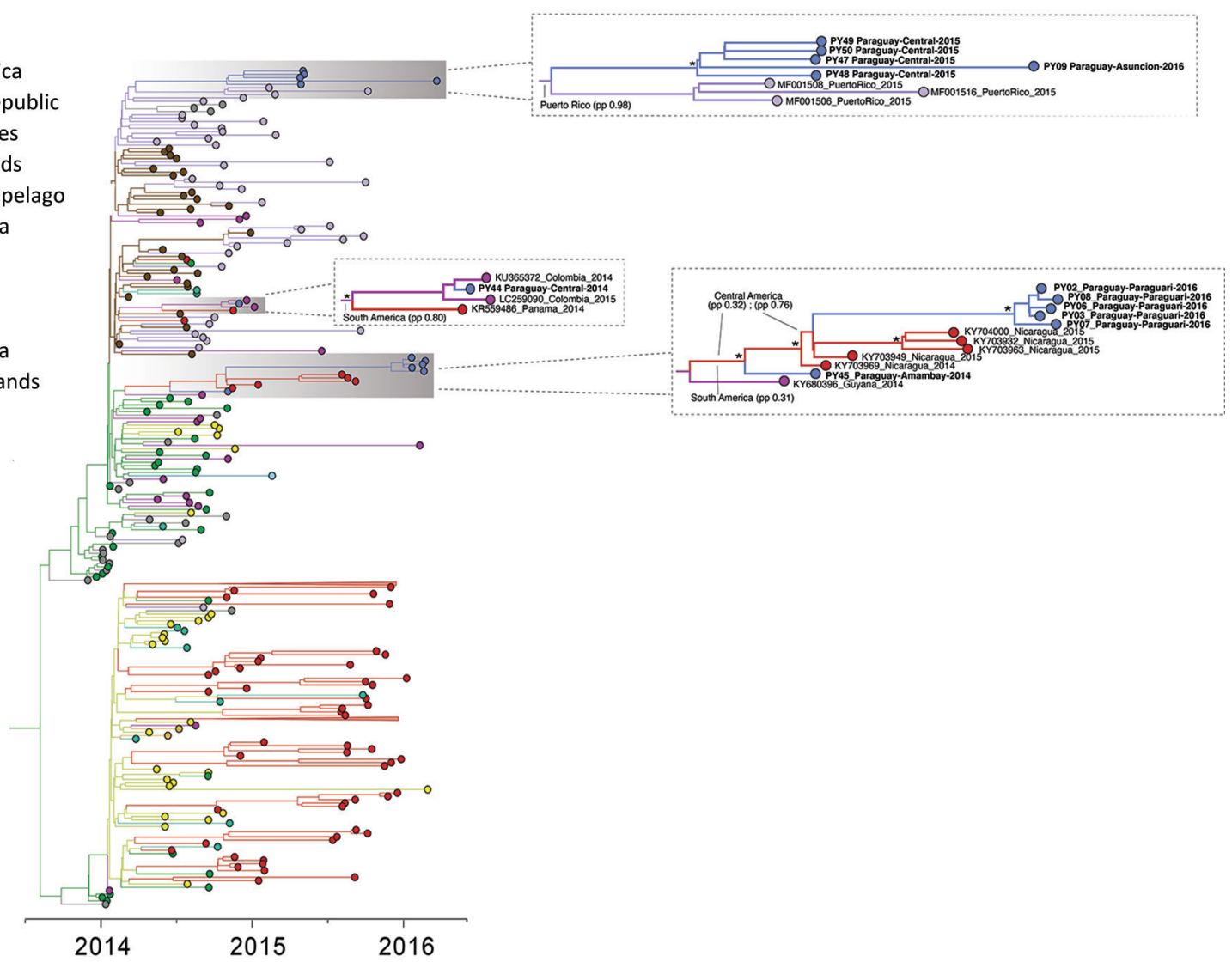

B

Northeast Brazil

North Brazil

Southeast Brazil

Central-Western Brazil

Paraguay

Haiti
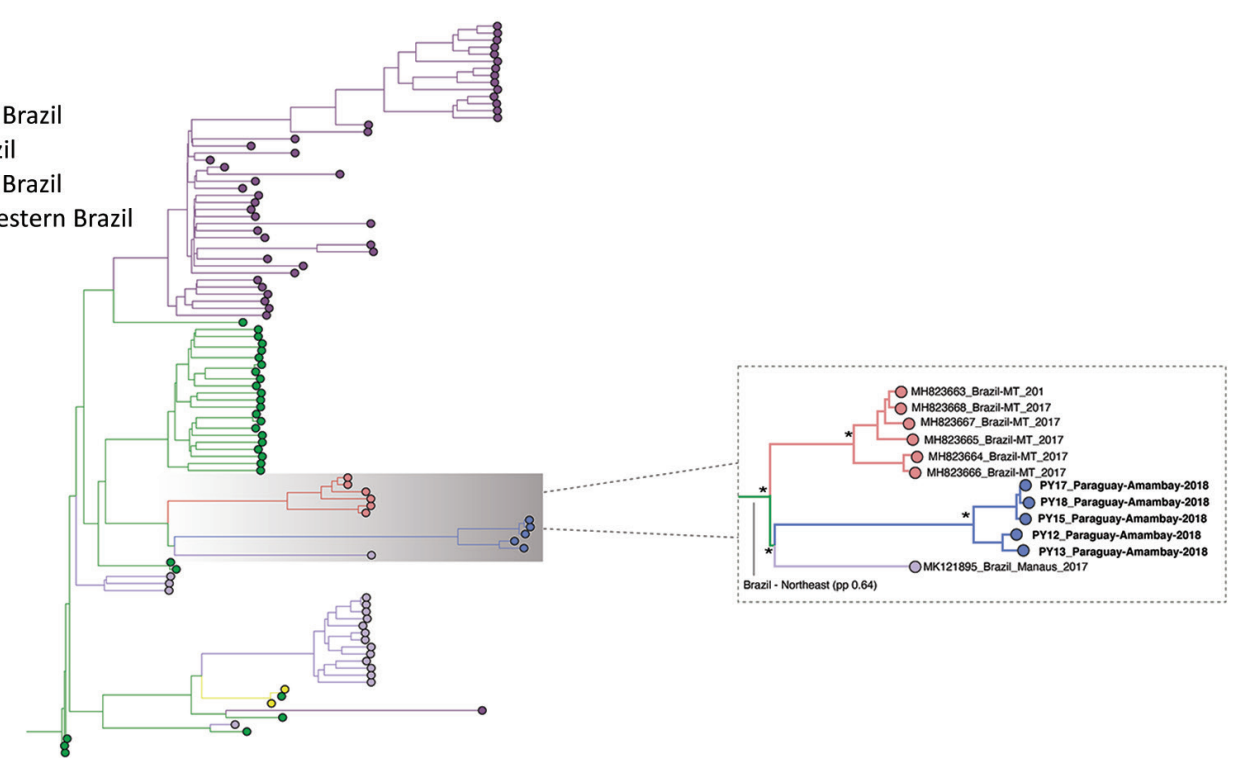

2014

2015

2016

2017

$2018 \quad 2019$

Figure 3. Time-scaled phylogenetic trees of chikungunya virus (CHIKV) genomes isolated in the Americas. A) CHIKV Asian genotype; B) CHIKV East/Central/South African genotype from Brazil. Tips and internal branches are colored according to the most likely geographic location, and ancestral states were estimated by phylogeographic methods. Clusters relevant to the epidemic in Paraguay are shown in detail where the most likely ancestral state estimation is annotated. Asterisks indicate highly supported clusters (posterior probability $>0.9$ ). 
from the 2015 epidemic, suggesting a new introduction event. However, because of the co-clustering of sequences from the Asunción and Central Departments isolated in 2015 and 2016, we cannot exclude year-round persistence of the virus. Models of Aedes spp. mosquito competence for DENV transmission have shown that the Paraguay climate is conducive to year-round persistence (29).

In Brazil, 2 distinct lineages of CHIKV were detected at the end of 2014, the ECSA genotype in the Northeast Region and the Asian genotype in the North Region (30). Whereas the CHIKV outbreak of the Asian genotype remained restricted to a small number of cases, the ECSA lineage spread throughout Brazil. In this study, we determined that the ECSA genotype was the causative agent of a CHIKV outbreak in Amambay (a Paraguay department on the Brazil border) in 2018. To our knowledge, these are the only 2 countries in the Americas to report outbreaks of both the Asian and ECSA genotypes to date. Our analysis revealed a mean time of entry into Paraguay of around December 2017, most likely from the Northeast Region in Brazil. However, because of the small number of samples from states in Brazil that border Paraguay, all such inferences of geographic origins should be interpreted with caution. It is possible that previous exposure to the CHIKV Asian genotype may have created some population immunity that restricted ECSA circulation in other parts of Paraguay (e.g., Central and Asunción Departments) in 2018. Unfortunately, no data on CHIKV seroprevalence in Paraguay are available to test this hypothesis. Amambay, on the other hand, reported few CHIKV cases during the epidemics of 2015 and 2016 (Figure 2 , panel A), potentially enabling the emergence of the ECSA genotype in 2018.
The 2018 dengue season in Paraguay was dominated by DENV-1, reported in all departments (9). Three departments (Central, Alto Paraná, and Guaira) also reported the circulation of DENV-4. Our analysis suggests that the origin of both serotypes in Paraguay is Brazil, supporting findings of previous studies (31). Although our sampling was restricted to 2018, we observed that the tMRCA of DENV-1 was much earlier (October 2016), suggesting that this lineage may have persisted during the 2017 and 2018 seasons, when it may have been responsible for most cases (9). DENV4 , on the other hand, was introduced in September 2017 , just before the start of the dengue season, and was responsible for few infections until the 2019-20 season, when it dominated the epidemic $(32,33)$.

Despite screening all publicly available (GenBank) sequences of DENV from the Americas, we found that the DENV datasets were sparsely distributed in time (DENV-4) or contained large temporal gaps (DENV-1) (Appendix 1 Figure 2), potentially biasing our results. The paucity of available DENV complete genomes in South America constrains the applicability of phylogenetic tools for studying virus population dynamics. It also highlights the value of intensifying sequencing efforts in line with the genomic surveillance approach and for real-time generating and sharing of data. The CHIKV datasets were much more comprehensive; for instance, the Asian lineage dataset analyzed included 291 genomes sampled during 2014-2018, representing 38 countries/territories (Appendix 2). The more comprehensive CHIKV datasets reflect the fact that CHIKV emerged in the Americas in the era of next-generation sequencing, when the development of numerous platforms reduced the cost and shortened the time from sample preparation to

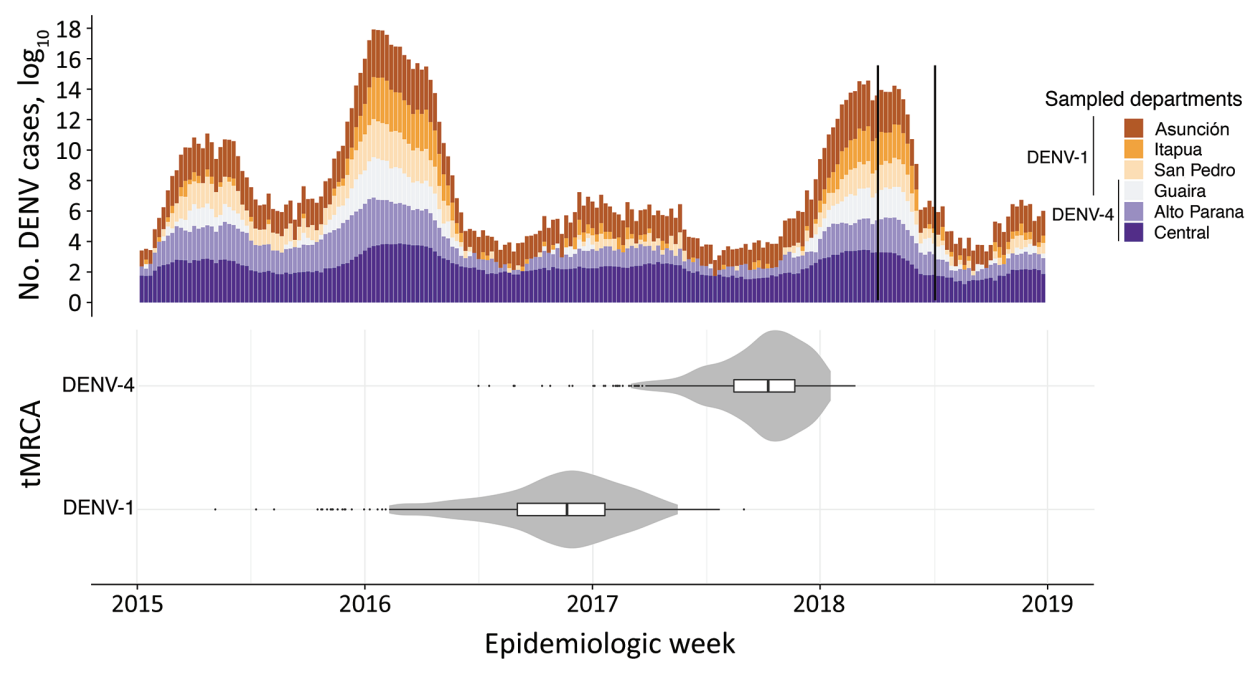

Figure 4. Dengue virus (DENV) outbreaks in Paraguay during 2015-2018 and tMCRA of serotypes 1 and 4 . A) Total cases of DENV infections reported by epidemiologic week in the departments from which genome sequences were available. The black bars in 2018 delimit the sampling time range for the DENV genomes. B) tMRCA for DENV-1 and DENV-4 in the same timescale as the number of cases reported. Violin plots show $95 \%$ Cls; internal boxplots show medians and interquartile ranges. tMCRA, time to most recent common ancestor. 


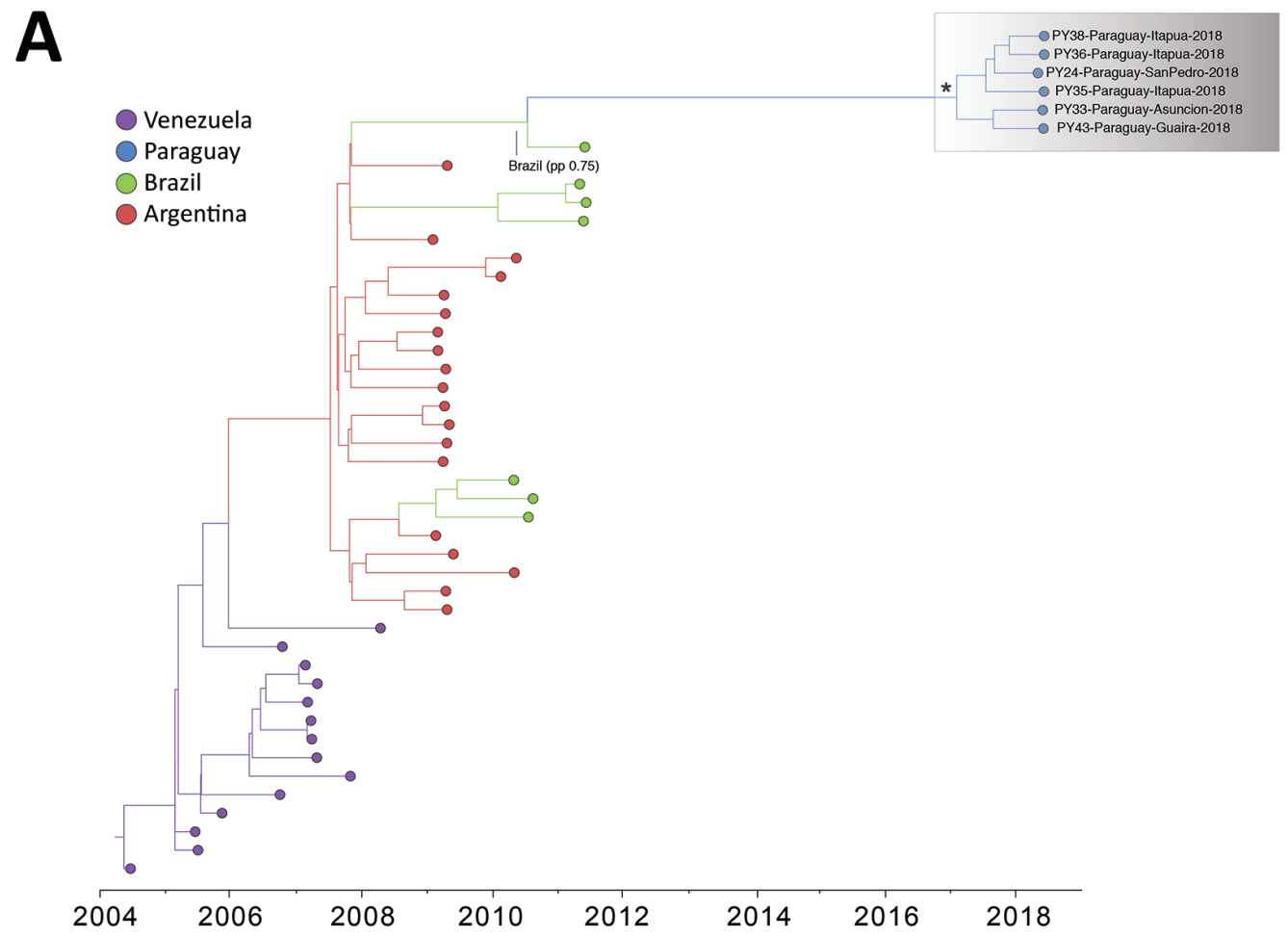

B

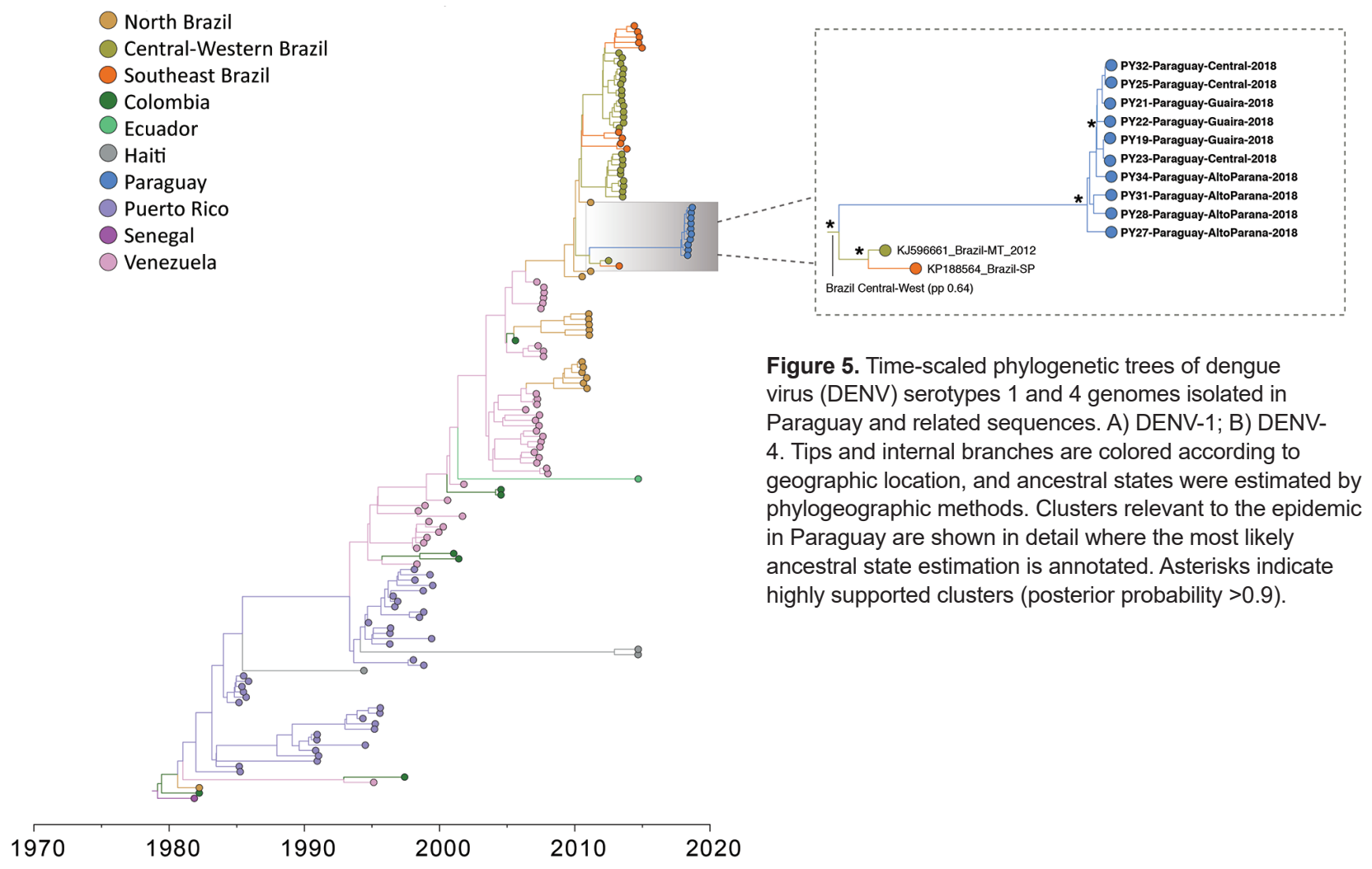


data generation. Hence, this increased availability of CHIKV virus genomes allowed a more detailed analysis of the virus's spatiotemporal history in Paraguay. However, another study limitation is the convenience sampling used, with a narrow breadth, potentially biasing molecular clock dating and location ancestral reconstruction. The limited availability of stored samples from years before 2018, and their possibly limited RNA integrity, impaired genome sequencing from previous outbreaks. Nevertheless, we suggest that the 33 genomes generated here are representative of the current DENV diversity and the recent CHIKV evolutionary history in Paraguay.

Of note, the mean tMRCAs for the 3 clusters of CHIKV and the 2 clusters of DENV were estimated in the last trimester of the year (SeptemberDecember), the start of arbovirus season in many tropical and subtropical regions in the Southern Hemisphere (e.g., Paraguay). A previous study (34) has modeled the timing and scale of arbovirus transmission potential and found that in many cities in Brazil with climates similar to that of Paraguay, transmission starts to increase around September. Thus, the tMRCAs estimated here probably reflect the onset of the arbovirus season, which peaks during January-March. Oddly, the 2017 season was marked by a noticeable reduction in cases of both DENV and CHIKV in Paraguay (Figure 2, panel A; Figure 5, panel A). This pattern was observed for dengue throughout the Americas, where cases decreased by $73 \%$ in 2017 compared with 2016 (35). It is possible that the mild season in 2017 might be explained by a transient strengthening of vector control interventions, implemented after the arrival of CHIKV and ZIKV in the Americas and the consequent public health emergency triggered by these pathogens. In addition, cross-immunity between ZIKV and DENV has been observed in the laboratory (36). Hence, population immunity to ZIKV after the 2015-2016 epidemic may have provided some transitory protection against DENV, resulting in lower incidence in $2017(37,38)$, although this protection alone would not explain the decreased CHIKV cases in 2017 in Paraguay.

In conclusion, our study reveals a complex pattern of arbovirus circulation in Paraguay. We identify Brazil as a source of CHIKV and DENV lineages and show that other countries from South America and the Caribbean, mainly tourist destinations, were also hubs of virus spread toward Paraguay. Our sequencing and phylogenetic analyses proved to be powerful tools for revealing the transmission dynamics between the sampled locations and matched, with striking precision, available patient travel history. With support from the Pan American Health Organization, this project developed capacity-building skills in Paraguay, which can be applied in future arbovirus outbreaks.

This work was supported by Decit/SCTIE/MoH and CNPq (440685/2016-8 and 440856/2016-7); by CAPES (88887.130716/2016-00, 88881.130825/2016-00, and $88887.130823 / 2016-00)$, and by the EU Horizon 2020 Programme through ZIKAlliance (PRES-005-FEX17-4-2-33). M.G. is supported by the Fundação de Amparo à Pesquisa do Estado do Rio de Janeiro-FAPERJ. E.C.H. is supported by an Australian Research Council Australian Laureate Fellowship (FL170100022). A.M.B.F. was supported by International Development Research Centre, Canada (grant 108411-001) and by Horizon 2020 through ZikaPlan and ZikAction (grant agreement nos. 734584 and 734857).

\section{About the Author}

Dr. Gräf is a public health researcher at the Gonçalo Moniz Institute of the Oswaldo Cruz Foundation, Salvador, Brazil. His research interests focus on molecular epidemiology and the application of phylogenetics to study viral evolution and epidemic spread.

\section{References}

1. Paixão ES, Teixeira MG, Rodrigues LC. Zika, chikungunya and dengue: the causes and threats of new and reemerging arboviral diseases. BMJ Glob Health 2018;3::e000530.

2. Kraemer MUG, Reiner RC Jr, Brady OJ, Messina JP, Gilbert M, Pigott DM, et al. Past and future spread of the arbovirus vectors Aedes aegypti and Aedes albopictus. Nat Microbiol. 2019;4:854-63. https:// doi.org/10.1038/ s41564-019-0376-y

3. Mayer SV, Tesh RB, Vasilakis N. The emergence of arthropod-borne viral diseases: a global prospective on dengue, chikungunya and zika fevers. Acta Trop. 2017;166:155-63. https:/ / doi.org/10.1016/j.actatropica. 2016.11.020

4. Pan American Health Organization. Health information platform for the Americas (PLISA) [cited 2019 Jan 29]. http:/ / www.paho.org/data/index.php/en

5. Vazquez C, Villalba S, Oviedo E, Gamarra ML, Oviedo E, Oviedo A, et al. Características virológicas y serológicas de pacientes con dengue grave y fallecidos por dengue durante la epidemia del año 2011 en Paraguay. Rev Inst Med Trop. 2012;77:8-18.

6. Flores Rodríguez LE, Díaz Duba S, Torales J, Agüero R, Román L, Adorno J, et al. Características clínicas de la epidemia de dengue en el Servicio de Urgencias del Hospital de Clínicas. Rev Salud Pública Paraguay. 2016;6:2-7.

7. Aquino VH, Anatriello E, Gonçalves PF, DA Silva EV, Vasconcelos PF, Vieira DS, et al. Molecular epidemiology of dengue type 3 virus in Brazil and Paraguay, 2002-2004. Am 
J Trop Med Hyg. 2006;75:710-5. https://doi.org/10.4269/ ajtmh.2006.75.710

8. Avilés G, Rowe J, Meissner J, Manzur Caffarena JC, Enria D, St Jeor S. Phylogenetic relationships of dengue-1 viruses from Argentina and Paraguay. Arch Virol. 2002;147:2075-87. https://doi.org/10.1007/s00705-002-0886-3

9. Direccion General de Vigilancia de la Salud. Paraguay. Boletín epidemiológico Semanal. 2018 [cited 2021 Mar 16]. http://dgvs.mspbs.gov.py/webdgvs/files/boletines/ SE52_2018_Boletin.pdf

10. Faria NR, Quick J, Claro IM, Thézé J, de Jesus JG, Giovanetti M, et al. Establishment and cryptic transmission of Zika virus in Brazil and the Americas. Nature. 2017;546:406-10. https://doi.org/10.1038/nature22401

11. Giovanetti M, Faria NR, Lourenço J, Goes de Jesus J, Xavier J, Claro IM, et al. Genomic and epidemiological surveillance of Zika virus in the Amazon Region. Cell Rep. 2020;30:2275-2283.e7. https://doi.org/10.1016/ j.celrep.2020.01.085

12. Faria NR, Kraemer MUG, Hill SC, Goes de Jesus J, Aguiar RS, Iani FCM, et al. Genomic and epidemiological monitoring of yellow fever virus transmission potential. Science. 2018;361:894-9. https://doi.org/10.1126/ science.aat7115

13. Giovanetti M, de Mendonça MCL, Fonseca V, Mares-Guia MA, Fabri A, Xavier J, et al. Yellow fever virus re-emergence and spread in Southeast Brazil, 2016-2019. J Virol. 2019;94:e01623-19. https://doi.org/10.1128/ JVI.01623-19

14. Naveca FG, Claro I, Giovanetti M, de Jesus JG, Xavier J, Iani FCM, et al. Genomic, epidemiological and digital surveillance of chikungunya virus in the Brazilian Amazon. PLoS Negl Trop Dis. 2019;13:e0007065. https:/ / doi.org/ 10.1371/journal.pntd.0007065

15. Pereira Gusmão Maia Z, Mota Pereira F, do Carmo Said RF, Fonseca V, Gräf T, de Bruycker Nogueira F, et al. Return of the founder chikungunya virus to its place of introduction into Brazil is revealed by genomic characterization of exanthematic disease cases. Emerg Microbes Infect. 2019;9:53-7. https:/ / doi.org/10.1080/22221751.2019.1701954

16. Xavier J, Giovanetti M, Fonseca V, Thézé J, Gräf T, Fabri A, et al. Circulation of chikungunya virus East/ Central/South African lineage in Rio de Janeiro, Brazil PLoS One. 2019;14:e0217871. https://doi.org/10.1371/ journal.pone.0217871

17. Lanciotti RS, Kosoy OL, Laven JJ, Velez JO, Lambert AJ, Johnson AJ, et al. Genetic and serologic properties of Zika virus associated with an epidemic, Yap State, Micronesia, 2007. Emerg Infect Dis. 2008;14:1232-9. https:/ / doi.org/ 10.3201/eid1408.080287

18. Lanciotti RS, Calisher CH, Gubler DJ, Chang GJ, Vorndam AV. Rapid detection and typing of dengue viruses from clinical samples by using reverse transcriptasepolymerase chain reaction. J Clin Microbiol. 1992;30:545-51. https://doi.org/10.1128/JCM.30.3.545-551.1992

19. Lanciotti RS, Kosoy OL, Laven JJ, Panella AJ, Velez JO, Lambert AJ, et al. Chikungunya virus in US travelers returning from India, 2006. Emerg Infect Dis. 2007;13:764-7. https://doi.org/10.3201/eid1305.070015

20. Quick J, Grubaugh ND, Pullan ST, Claro IM, Smith AD, Gangavarapu K, et al. Multiplex PCR method for MinION and Illumina sequencing of Zika and other virus genomes directly from clinical samples. Nat Protoc. 2017;12:1261-76. https:/ / doi.org/10.1038/nprot.2017.066

21. Fonseca V, Libin PJK, Theys K, Faria NR, Nunes MRT, Restovic MI, et al. A computational method for the identification of dengue, Zika and chikungunya virus species and genotypes. PLoS Negl Trop Dis. 2019;13: e0007231. https:/ / doi.org/10.1371/journal.pntd.0007231

22. Katoh K, Kuma K, Toh H, Miyata T. MAFFT version 5: improvement in accuracy of multiple sequence alignment. Nucleic Acids Res. 2005;33:511-8. https:/ / doi.org/10.1093/ nar/gki198

23. Larsson A. AliView: a fast and lightweight alignment viewer and editor for large datasets. Bioinformatics. 2014;30:3276-8. https://doi.org/10.1093/bioinformatics/btu531

24. Nguyen LT, Schmidt HA, von Haeseler A, Minh BQ. IQ-TREE: a fast and effective stochastic algorithm for estimating maximum-likelihood phylogenies. Mol Biol Evol. 2015;32:268-74. https://doi.org/10.1093/molbev/msu300

25. Rambaut A, Lam TT, Max Carvalho L, Pybus OG. Exploring the temporal structure of heterochronous sequences using TempEst (formerly Path-O-Gen). Virus Evol. 2016;2:vew007. https://doi.org/10.1093/ve/vew007

26. Suchard MA, Lemey P, Baele G, Ayres DL, Drummond AJ, Rambaut A. Bayesian phylogenetic and phylodynamic data integration using BEAST 1.10. Virus Evol. 2018;4:vey016. https://doi.org/10.1093/ve/vey016

27. Lemey P, Rambaut A, Drummond AJ, Suchard MA. Bayesian phylogeography finds its roots. PLOS Comput Biol. 2009;5:e1000520. https://doi.org/10.1371/journal.pcbi.1000520

28. Leparc-Goffart I, Nougairede A, Cassadou S, Prat C, de Lamballerie X. Chikungunya in the Americas. Lancet. 2014;383:514. https:/ / doi.org/10.1016/ S0140-6736(14)60185-9

29. Brady OJ, Golding N, Pigott DM, Kraemer MU, Messina JP, Reiner RC Jr, et al. Global temperature constraints on Aedes aegypti and Ae. albopictus persistence and competence for dengue virus transmission. Parasit Vectors. 2014;7:338. https://doi.org/10.1186/1756-3305-7-338

30. Nunes MRT, Faria NR, de Vasconcelos JM, Golding N, Kraemer MU, de Oliveira LF, et al. Emergence and potential for spread of chikungunya virus in Brazil. BMC Med. 2015;13:102. https://doi.org/10.1186/s12916-015-0348-x

31. de Bruycker-Nogueira F, Souza TMA, Chouin-Carneiro T, da Costa Faria NR, Santos JB, Torres MC, et al. DENV-1 genotype $\mathrm{V}$ in Brazil: spatiotemporal dispersion pattern reveals continuous co-circulation of distinct lineages until 2016. Sci Rep. 2018;8:17160. https://doi.org/10.1038/ s41598-018-35622-x

32. Direccion General de Vigilancia de la Salud. Paraguay.Boletín epidemiológico Semanal. 2019 [cited 2021 Mar 16]. http:/ / dgvs.mspbs.gov.py/files/boletines/SE40_2019_Boletin.pdf

33. Direccion General de Vigilancia de la Salud. Paraguay. Boletín epidemiológico Semanal, 2020 [cited 2021 Mar 16]. http:/ /dgvs. mspbs.gov.py/files/boletines/SE40_2020_Boletin.pdf

34. Obolski U, Perez PN, Villabona-Arenas CJ, Thézé J, Faria NR, Lourenço J. MVSE: an R-package that estimates a climatedriven mosquito-borne viral suitability index. Methods Ecol Evol. 2019;10:1357-70. https://doi.org/10.1111/ 2041-210X.13205

35. Perez F, Llau A, Gutierrez G, Bezerra H, Coelho G, Ault S, et al. The decline of dengue in the Americas in 2017: discussion of multiple hypotheses. Trop Med Int Health. 2019;24:442-53. https://doi.org/10.1111/tmi.13200

36. Priyamvada L, Quicke KM, Hudson WH, Onlamoon N, Sewatanon J, Edupuganti S, et al. Human antibody responses after dengue virus infection are highly cross-reactive to Zika virus. Proc Natl Acad Sci U S A. 2016;113:7852-7. https://doi.org/10.1073/pnas.1607931113

37. Pérez-Guzmán EX, Pantoja P, Serrano-Collazo C, Hassert MA, Ortiz-Rosa A, Rodríguez IV, et al. Time elapsed between Zika 
and dengue virus infections affects antibody and T cell responses. Nat Commun. 2019;10:4316. https://doi.org/ 10.1038/s41467-019-12295-2

38. Mugabe VA, Borja LS, Cardoso CW, Weaver SC, Reis MG, Kitron $\mathrm{U}$, et al. Changes in the dynamics of dengue incidence in South and Central America are possibly due to crosspopulation immunity after Zika virus epidemics. Trop Med Int Health. 2021:26:272-80.
Address for correspondence: Luiz Carlos Junior Alcantara, Laboratório de Flavivirus, Instituto Oswaldo Cruz, Fundação Oswaldo Cruz, Rio de Janeiro, RJ, Brazil; email: luiz.alcantara@ ioc.fiocruz.br; Jairo Andrés Méndez Rico, Pan American Health Organization/World Health Organization, 525 23rd St NW, Washington, DC 20037, USA; email: ricoj@paho.org

\section{February 2021}

\section{Vectorborne Infectious Diseases}

- Childcare Exposure to Severe Acute Respiratory Syndrome Coronavirus 2 for 4-Year-Old Presymptomatic Child, South Korea

- Characteristics of Patients Co-infected with Severe Acute Respiratory Syndrome Coronavirus 2 and Dengue Virus, Buenos Aires, Argentina, MarchJune 2020

- Characteristics and Timing of Initial Virus Shedding in Severe Acute Respiratory Syndrome Coronavirus 2, Utah, USA

- Zika Virus-Associated Birth Defects, Costa Rica, 2016-2018

- Plasmodium ovale wallikeri and $P$. ovale curtisi Infections and Diagnostic Approaches to Imported Malaria, France, 2013-2018

- Symptom Profiles and Progression in Hospitalized and Nonhospitalized Patients with Coronavirus Disease, Colorado, USA, 2020

- Addressing COVID-19 Misinformation on Social Media Preemptively and Responsively

- Universal Admission Screening for SARS-CoV-2 Infections among Hospitalized Patients, Switzerland, 2020

- Excess Deaths during Influenza and Coronavirus Disease and Infection-Fatality Rate for Severe Acute Respiratory Syndrome Coronavirus 2, the Netherlands

- Murine Typhus in Canary Islands, Spain, 1999-2015

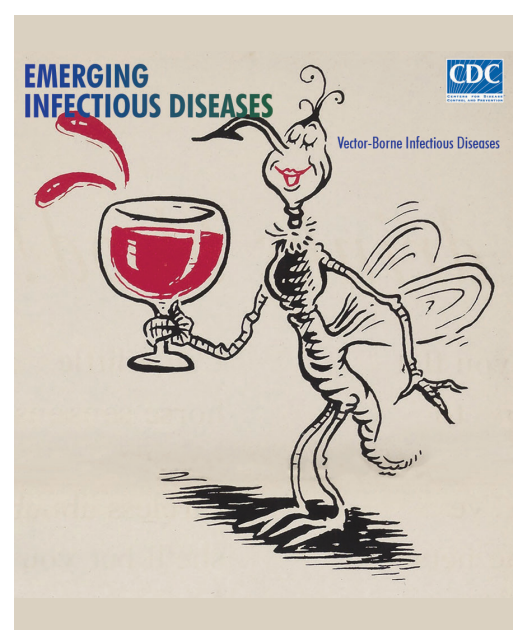

- Rapid Transmission of Severe Acute Respiratory Syndrome Coronavirus 2 in Detention Facility, Louisiana, USA, May-June, 2020

- Plasma MicroRNA Profiling of Plasmodium falciparum Biomass and Association with Severity of Malaria Disease

- Increasing Incidence of Invasive Group A Streptococcus Disease in First Nations Population, Alberta, Canada, 2003-2017

- Outbreak of Severe Vomiting in Dogs Associated with a Canine Enteric Coronavirus, United Kingdom

- Spread of Multidrug-Resistant Rhodococcus equi, United States

- SARS-CoV-2 Infections among Recent Organ Recipients, MarchMay 2020, United States
- Plasmodium falciparum HistidineRich Protein 2 and

3 Gene Deletions in Strains from Nigeria, Sudan, and South Sudan

- Hepatitis C Virus Transmission Clusters in Public Health and Correctional Settings, Wisconsin, USA, 2016-2017

- Prolonged Maternal Zika Viremia as a Marker of Adverse Perinatal Outcomes

- Use of Commercial Claims Data for Evaluating Trends in Lyme Disease Diagnoses, United States, 2010-2018

- Highly Pathogenic Avian Influenza A(H5N8) Virus Spread by Shortand Long-Range Transmission, France, 2016-17

- Emergence of Lyme Disease on Treeless Islands, Scotland, United Kingdom

- SARS-CoV-2 Transmission between Mink (Neovison vison) and Humans, Denmark

- Shuni Virus in Cases of Neurological Disease in Humans, South Africa

- SARS-CoV-2 Transmission between Mink (Neovison vison) and Humans, Denmark

- Effects of Social Distancing Measures during the First Epidemic Wave of Severe Acute Respiratory Syndrome Coronavirus 2, Greece
EMERGING INFECTIOUS DISEASES
To revisit the February 2021 issue, go to: https://wwwnc.cdc.gov/eid/articles/issue/27/2/table-of-contents 